\title{
Synergism of Zinc Oxide Nano-Powder with Active Compound from Turmeric and Lemongrass as Bacterial Inhibitor
}

\author{
Gee Een LAU ${ }^{1}$, Che Azurahanim CHE ABDULLAH, ${ }^{2, *}$, \\ Mohd Sabri MOHD GHAZALI ${ }^{3}$ and Muhamad Syazlie CHE IBRAHIM ${ }^{4}$ \\ ${ }^{1}$ Material Synthesis and Characterization Laboratory, Institute of Advanced Technology (ITMA), \\ Universiti Putra Malaysia, Selangor, Malaysia \\ ${ }^{2}$ Department of Physics, Faculty of Science, Universiti Putra Malaysia, Selangor, Malaysia \\ ${ }^{3}$ Department of Nano Physics, Universiti Malaysia Terengganu, Terenggganu, Malaysia \\ ${ }^{4}$ Department of Biological Science, Universiti Malaysia Terengganu, Terengganu, Malaysia
}

('Corresponding author's e-mail: azurahanim@upm.edu.my)

Received: 13 March 2020, Revised: 19 May 2020, Accepted: 9 June 2020

\begin{abstract}
Green nanoparticles are receiving great attention due to their broad fields of application. Plant extracts are promising sources, since the synergizing process is easy and cost-effective. Green synergism offers safer nanomaterials for both human health and the environment. The antimicrobial application of prepared nanoparticles is due to special capabilities at the nanoscale size. Green zinc oxide nanoparticles (ZnONPs) from lemongrass and turmeric revealed good antibacterial properties. Antibacterial active compounds were extracted from lemongrass and turmeric using methanol as a solvent. The extracts were introduced to zinc oxide solution to create synergized green ZnONPs and tested for their antibacterial properties. The samples were characterized by means of XRD, SEM, FTIR, and GC-MS. The zones of inhibition of synergized green ZnONPs were successfully measured using the disc diffusion method. The findings using gram-negative bacteria Escherichia coli. showed a higher antibacterial inhibition zone, with a diameter of $1.6 \mathrm{~cm}$. The gram-positive bacteria, Staphylococcus aureus., showed low antibacterial inhibition. The addition of $\mathrm{ZnO}$ had positively revealed greater inhibition. Green $\mathrm{ZnONPs}$ synthesized using plant extracts will be further tested for various applications.
\end{abstract}

Keywords: Metal oxide, Green synergism, Escherichia coli, Synergism, Green product, Active Compound, Turmeric, Lemongrass, Bacterial inhibitor

\section{Introduction}

Nanomedicine involves the use of nanotechnology for the benefit of human health [1,2]. Drug delivery, therapy techniques, diagnostic techniques, antimicrobial techniques, and cell repair are among the examples it could be used for [3-5]. Synergistic combinations in nanomedicine exhibit increasing importance in therapy, due to their ability to deliver the best quality therapeutic effects. Synergism refers to the process of 2 or more agents combining to produce a greater effect compared to their individual effects [6]. The opposite brings a weaker effect, known as antagonism and indifference, or additive to those which bring almost similar effects. A synergistic process may lead to a new reaction, or develop existing reactions, leading to significant industrial development. Allen and Macmillan suggested synergism may produce a new and effective product and improve existing products [7]. Both oxidation and reduction take place during the synergism of nanoparticles with plant extracts [8,9]. Plant extracts contain very rich resources of biomolecules, and most of them are low in cost [10]. Plant extracts are significant in reducing and stabilizing metallic ions. Lemongrass (Cymbopogon citratus) and turmeric 
http://wjst.wu.ac.th

(Curcuma Longa) have been extensively studied to enhance their antibacterial activity $[11,12]$.

Zinc oxide is applied on skin to treat wounds and ulcers, stop acne, remove psoriasis, help against eczema, heal skin, and relieve melasma $[8,13]$. Extensive research is leading to new antimicrobial medicines which are isolated from different sources. Bacterial infections are a major source of various infectious diseases $[14,15]$. Pure green antimicrobial agent is less effective compared to antimicrobial chemical agents [16]. Thus, metal oxide is introduced into pure extracts to enhance their antimicrobial abilities. The synergism of metal oxide and plant extracts allows the activation of metal ions from the mono or divalent oxidation states to zero-valent states. The nucleation of reduced metal atoms then takes place. Neighboring particles will accumulate to form larger nanoparticles that are thermodynamically stable [17]. The current study focuses on the synergism of zinc oxide nanoparticles with 2 plant extracts. The measurement of the zones of inhibition determines their effectiveness as antimicrobial agents.

\section{Materials and methods}

\section{Samples of lemongrass and turmeric}

Fresh lemongrass (Cymbopogon citratus) and turmeric (Curcuma Longa) were bought from Serdang, Selangor. The species of plants were obtained from the same source and were verified as per Tajidin et al. in 2012 and Alafiatayo et al. in 2014 [18,19]. They were washed and rinsed with distilled water to remove unwanted constituents. Then, they were cut into small pieces and dried at $50{ }^{\circ} \mathrm{C}$ for $48 \mathrm{~h}$. The dried samples were ground into powder form. The weights before and after drying were recorded to obtain the results of moisture loss.

\section{Extract preparation}

The preparation of lemongrass and turmeric extracts was carried out using the method of Balakrishnan et al. in 2014 with some modification. The active compounds from lemongrass and turmeric were obtained by soaking $30 \mathrm{~g}$ of turmeric and lemongrass powder in $300 \mathrm{~mL}$ of methanol (99\%), respectively. The suspensions were then stirred for $24 \mathrm{~h}$ by an orbital shaker at $250 \mathrm{rpm}$ at room temperature. The solution was then filtered using filter paper (Smith, $110 \mathrm{~mm}$ ) prior to separation via a vacuum pump evaporator. This step ensured that the methanol had been completely removed from the active compounds. The solution was stored in $4{ }^{\circ} \mathrm{C}$ and away from sunlight to prevent any contamination $[20]$.

\section{Synergism process}

During the synergism process, $0.10 \mathrm{~g}$ of zinc oxide nano-powder were added into $1.00 \mathrm{~mL}$ of deionized water. The solution was stirred using a magnetic stirrer to ensure the sample was homogenous. The resulting zinc oxide solution was added into lemongrass and turmeric extract, respectively, in a 1:1 ratio mode. The suspensions were then probe sonicated to obtain homogenous antibacterial agents for further use [21].

\section{Sample characterizations}

X-ray analysis was accomplished using PW 3040/60 MPD X' pert Pro Panalytical Philips DY 1861 $\mathrm{X}$-ray diffractometer. A $\mathrm{Cu}-\mathrm{K} \alpha$ radiation source with $\lambda=1.5406 \AA$, which operated at $40 \mathrm{~mA}$ and $40 \mathrm{Kv}$, was used. All samples were mounted on sample holders. The measurements were carried out over $2 \theta$ scans over diffraction angles from $20^{\circ}$ to $80^{\circ}$ with a speed of $2.00^{\circ} / \mathrm{min}$. The step size for scanning was $0.03^{\circ}$. X-ray analysis was performed to further confirm the action of the pure zinc oxide phase of the nanoparticles [22]. The significant peaks of the prepared nano-powder could be calculated by using Scherrer's formula:

$D=K \lambda /(\beta \cos \theta)$

where $\mathrm{D}$ refers to the average crystallite size, $\beta$ is the full width at half maximum (FWHM) line broadening in radians, $\theta$ is the Bragg diffraction angle, $\lambda$ is the X-ray wavelength used (1.54060 $\AA$ ), and 
http://wjst.wu.ac.th

$\mathrm{K}$ is the dimensionless shape factor approximately equal to 0.94 [23]. Fourier Transform Infrared (FTIR) Spectroscopy (SHIMADZU IR-Tracer 100) was used to identify the functional groups in the plant extracts and antibacterial agents [24]. The spectrums were scanned in the frequency range of 4,000 to 400 $\mathrm{cm}^{-1}$ with spectra resolution of $4 \mathrm{~cm}^{-1}$ under transmittance mode. After the background emission spectrum of the infra-red source was recorded, the emission spectrum of the infrared source with the sample was observed. The resultant absorption spectrum from the bond natural vibration frequencies indicated the presence of the chemical bonds and functional groups present in the sample. A Scanning Electron Microscope (SEM) (JEOL) was used to observe the shape of the zinc oxide nano-powder in this research [25]. SEM images were seen in different magnification ranges, such as X65, X200, and X4500. Gas Chromatography-Mass Spectrometer (GC-MS) was used to scrutinize complex organic matter in the pure extract of lemongrass and turmeric [26]. This were analyzed by using a Shimadzu Gas Chromatograph (Model GCMS-QP2010 Plus) coupled with a non-polar Rtx-MS capillary column $30 \mathrm{~m}$ in length, 0.25 $\mathrm{mm}$ in diameter, and $0.25 \mu \mathrm{L}$ in thickness, using a mass spectrometer detector, and helium was used as the carrier gas.

\section{Antibacterial activity}

The antibacterial activity was evaluated by using the disc diffusion method. Escherichia coli is gram-negative bacteria, having a thin peptidoglycan layer with an outer membrane. Staphylococcus aureus is gram-positive bacteria, having a thick peptidoglycan layer without an outer lipid membrane. The presence of these bacteria in water is one of the roots of various diseases and infections [27]. Sterilized paper discs were immersed in the prepared antibacterial agent. Following air drying, samples were then placed on the inoculated agar. The agar was inoculated with either Escherichia coli or Staphylococcus aureus. Their findings revealed the respective effectiveness. The inoculated agar was divided into 4 segments per petri dish. After incubation of $37{ }^{\circ} \mathrm{C}$ for $24 \mathrm{~h}$, the levels of the zones of inhibition of bacteria were measured. Three sets of replicates were done for each set to obtain average results. The measurement of antibacterial activity was carried out as shown in Figure 1.
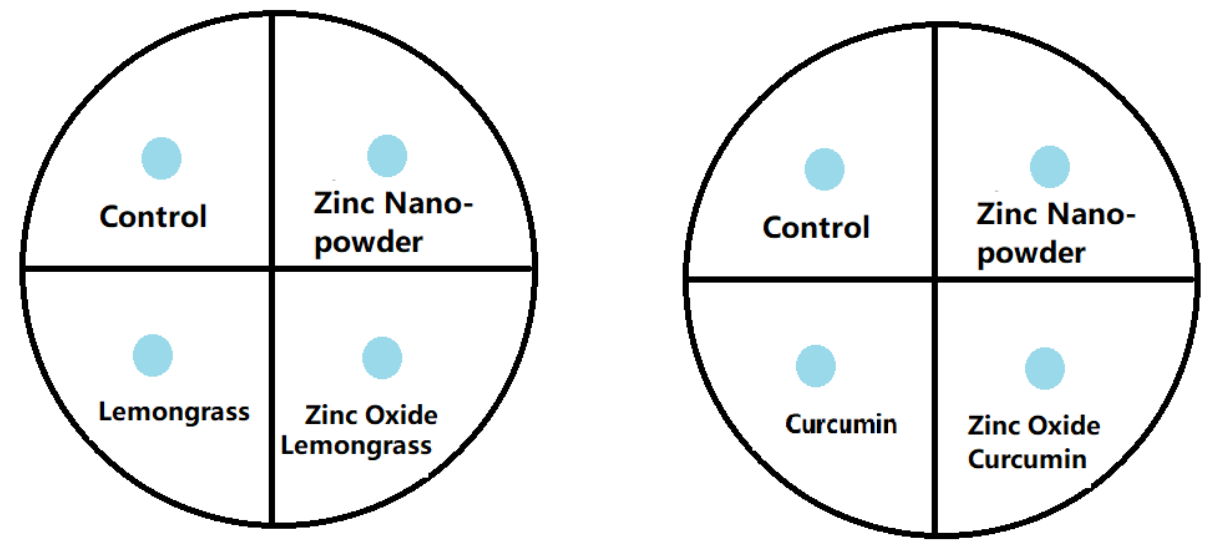

Figure 1 Design of antibacterial activities.

\section{Results and discussion}

\section{Loss of moisture}

Table 1 shows the weights of turmeric and lemongrass before and after the drying process. The data revealed that, after the weighing process, there was a great decrease in the weights of both samples, due to the loss of moisture content. This process was to ensure that the samples were completely dried. Then, samples were ground into powder instead of paste. Apart from changes in weight, the colour of the samples also changed following the drying process. 
http://wjst.wu.ac.th

Table 1 Mass of turmeric and lemongrass before and after drying.

\begin{tabular}{ccc}
\hline Condition & Mass of Turmeric (g) & Mass of Lemongrass (g) \\
\hline Before Drying & 500.0 & 500.0 \\
After Drying & 47.2 & 54.4 \\
\hline
\end{tabular}

The initial moisture content (\%) for each plant was calculated by using Eq. (2). The results are tabulated in Table 2.

Initial moisture content $(\%)=\frac{M 1-M 2}{M 1} \times 100 \%$

where M1 is the mass before drying, while M2 is the mass after drying.

Table 2 Initial moisture content of turmeric and lemongrass.

\begin{tabular}{ll}
\hline Type of Antibacterial Agent & Moisture Content \\
\hline Turmeric & 90.56 \\
Lemongrass & 89.12 \\
\hline
\end{tabular}

From these findings, it was proven that the moisture in the plants had been lost. Moisture in the plant extract may have led to oxidation, which would have caused the compound in the extract to become unstable. In addition, higher water content would have promoted the growth of fungi [28].

\section{Characterization of samples}

Figure 2 shows the spectrum of as-received $\mathrm{ZnO}$ nano-powder. The diffraction pattern was found with $2 \theta$ from $20^{\circ}$ to $80^{\circ}$.

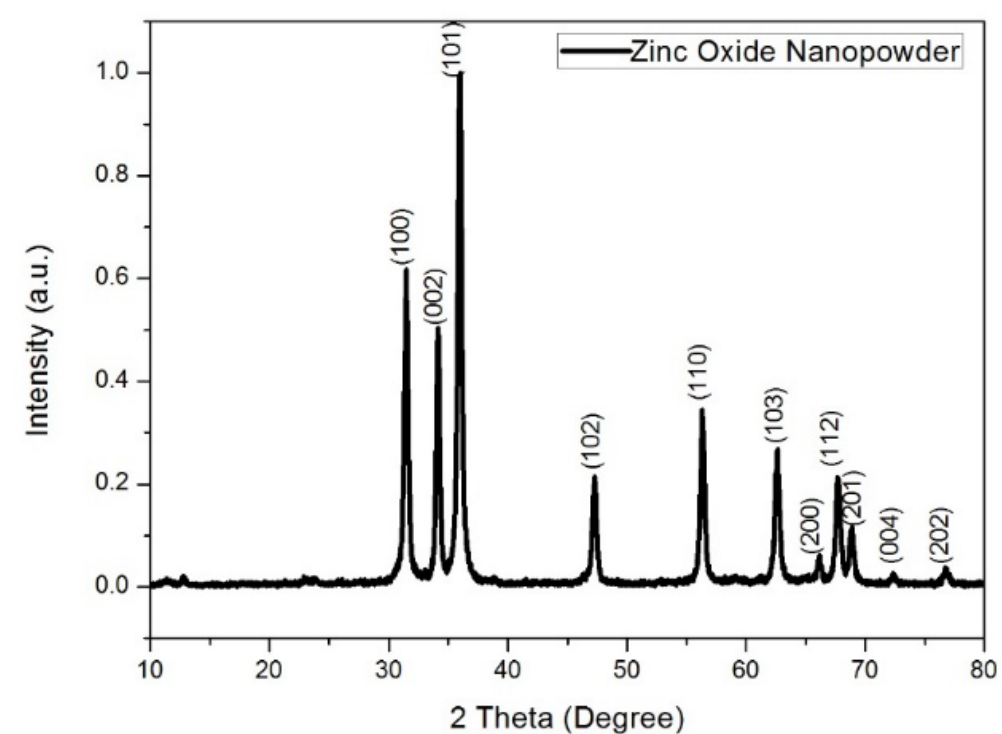

Figure 2 XRD spectra of as-received $\mathrm{ZnO}$ nano-powder. 
The XRD spectra of $\mathrm{ZnO}$ nano-powder from Figure 2 shows that $\mathrm{ZnO}$ nano-powder is a metal oxide with a pure hexagonal structure with a lattice parameter of $\mathrm{a}=3.25 \AA$ and $\mathrm{c}=5.20 \AA$. The peaks revealed at $2 \theta$ range of $31.41^{\circ}, 34.14^{\circ}, 35.77^{\circ}, 47.22^{\circ}, 56.30^{\circ}, 62.66^{\circ}, 67.75^{\circ}, 69.01^{\circ}, 72.09^{\circ}$, and $76.82^{\circ}$ correspond to pure $\mathrm{ZnO}$. The highest intensity peak (101) plane of zinc oxide, was observed, with other smaller intensity peaks of 100,002, 102, 110, 103, 200,112, 201, 004, and 202 [29]. There were no other irrelevant peaks. The crystallite size was calculated based on Scherrer's equation, as shown in Eq. (1). The average calculated crystallite size was found to be $17.45 \mathrm{~nm}$. The results obtained are in line with the data reported by Zak et al. [30].

The FTIR spectrum for zinc oxide nano-powder and solution was in the range of $400 \mathrm{~cm}^{-1}$ to 4,000 $\mathrm{cm}^{-1}$. As shown in Figure 3(a), the sharp transmittance peak at $434.33 \mathrm{~cm}^{-1}$ shows the characteristic stretching mode of the $\mathrm{Zn}-\mathrm{O}$ bond [31]. The peak at $1,628.37 \mathrm{~cm}^{-1}$ represents the asymmetric and symmetric stretching of acetate species. A strong peak was observed at $3,312.54 \mathrm{~cm}^{-1}$, which represents the presence of water molecules in the sample. Since the zinc oxide nano-powder was diluted into zinc oxide solution, the peak which indicates the $\mathrm{O}-\mathrm{H}$ bond was shifted.
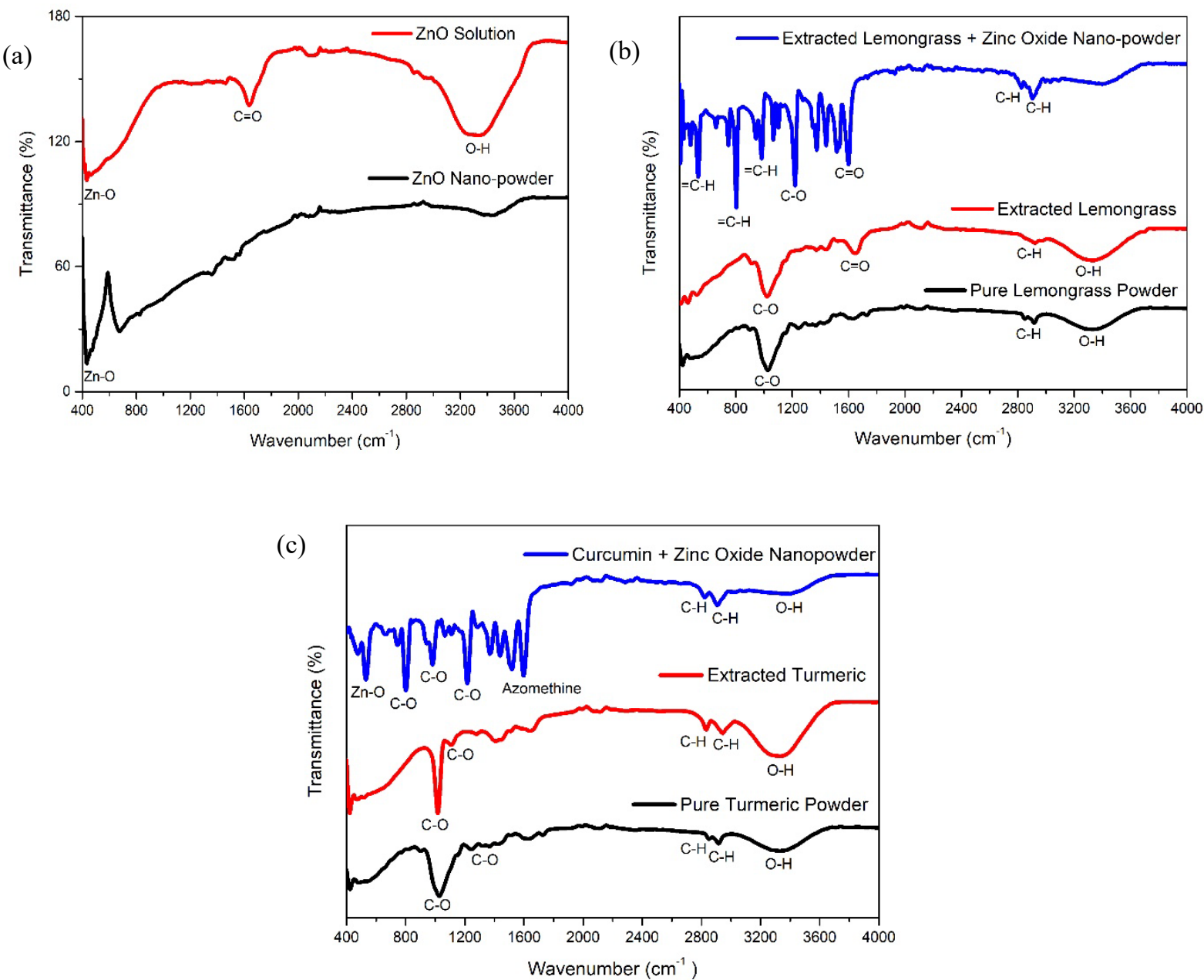

Figure 3 FTIR spectra of (a) ZnO nano-powder and $\mathrm{ZnO}$ solution; (b) pure lemongrass powder, extracted lemongrass, and synergism of extracted lemongrass with zinc oxide nano-powder; (c) pure turmeric powder, extracted turmeric, and synergism of curcumin with zinc oxide nanopowder. 
Figure 3(b) shows that the FTIR spectra for pure lemongrass powder and extracted lemongrass were almost the same. The only small difference was the observable peak at $1,661.45 \mathrm{~cm}^{-1}$ in extracted lemongrass, but this was not present in pure lemongrass powder. The peaks observed were at 3,337.18 $\mathrm{cm}^{-1}$ in the spectrum of pure lemongrass powder and $3,326.73 \mathrm{~cm}^{-1}$ in extracted lemongrass. These peaks showed the stretching region of the hydroxyl group $\mathrm{O}-\mathrm{H}$. They indicated the presence of water in pure lemongrass powder. A few bands of alkanes $(\mathrm{C}-\mathrm{H})$ were shown at $2,850-3,000 \mathrm{~cm}^{-1}$. Generally, the carbonyl group with $\mathrm{C}=\mathrm{O}$ was in the range of $1,660-1,820 \mathrm{~cm}^{-1}$. The spectrum of extracted lemongrass peak was at $1,661.45 \mathrm{~cm}^{-1}$. This peak revealed a cyclodextrin complex formation, with the molecules possessing the carbonyl group. This peak also revealed that the active compound of lemongrass was successfully extracted. The bands appeared at 1,000 to $1,260 \mathrm{~cm}^{-1}$, indicating the presence of the ether group C-O. These findings are in line with the results reported by Anvekar et al. [32]. The synergism of lemongrass and zinc oxide nano-powder showed a peak of $1,603.23 \mathrm{~cm}^{-1}$, which indicated the carbonyl group $\mathrm{C}=\mathrm{O}$ was shifted and became more intense. This indicated that the cyclodextrin complex between the carbonyl group of lemongrass and zinc oxide nanopowder had occurred perfectly. The alkane bands $\mathrm{C}-\mathrm{H}$ were shown at $2,910.97 \mathrm{~cm}^{-1}$. The bending bands at 675 to $1,000 \mathrm{~cm}^{-1}$ indicated the presence of the alkene $=\mathrm{C}-\mathrm{H}$ group.

Figure 3(c) shows the FTIR spectra of pure, extracted turmeric, and the synergism of extracted turmeric with zinc oxide nano-powder. Turmeric contains different fatty acids. One of the important essential oils in turmeric is oleic acid in the range of 1,040 to $1,290 \mathrm{~cm}^{-1}[33,34]$. Spectra of pure and extracted turmeric shared similar prominent peaks and functional groups. However, the bands of extracted turmeric for alkanes $\mathrm{C}-\mathrm{H}$ were more intense than in pure turmeric powder. This indicated that the extraction process of turmeric produced similar components as those of the initial pure turmeric powder. The turmeric extract was found to produce similar components as those of initial pure turmeric. Slight differences observed may have been due to the increment of the oil chain. This process is known as polymerization [35]. The results agreed with the previous research discovered by Araujo et al. in 2016. These 3 spectra were associated with the stretching region of the hydroxyl group O-H. The spectra of biofunctionalized curcumin and zinc oxide nanopowder was exhibited at $1,607.71 \mathrm{~cm}^{-1}$. This peak was associated with the azomethine compound of curcuminaniline which interacted with zinc oxide nanoparticles [36]. The characteristic peaks in the range of $1,350-1,520 \mathrm{~cm}^{-1}$ revealed the aromatic unsaturation $\mathrm{C}=\mathrm{C}$ of stabilized curcumin system, and the $\mathrm{C}-\mathrm{O}$ band presence was shown peaks at 985.20 and $1,221.07 \mathrm{~cm}^{-1}$. There were no bands occurring in the carbonyl region which laid between 1,650 to $1,800 \mathrm{~cm}^{-1}$. This indicated curcumin presence in keto-enol tautomeric form [37]. The peak at $523.16 \mathrm{~cm}^{-1}$ in the synergism of curcumin and zinc oxide nano-powder suggested the presence of an altered $\mathrm{Zn}-\mathrm{O}$ bond. This bond was due to its interaction with curcumin [38]. The functional group observed was identical to the results as reported by Moussawi and Patra in 2016. 

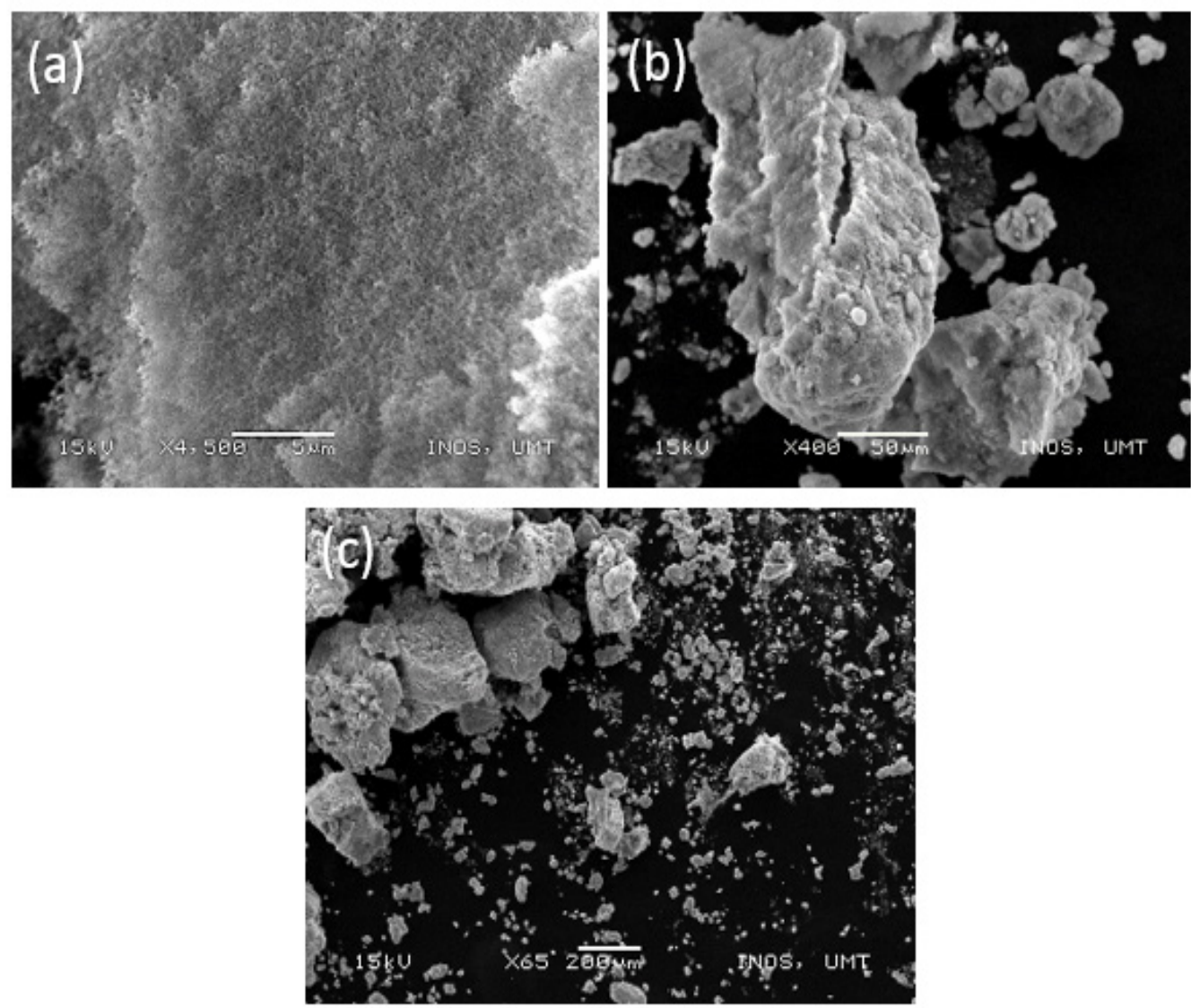

Figure 4 Images of $\mathrm{ZnO}$ nano-powder under SEM in magnification range of (a) X4500; (b) X400; (c) X65.

Figures 4(a) - 4(c) show the SEM images of $\mathrm{ZnO}$ nanoparticles. In Figure 2(a), the image was under X4500 magnification. The $\mathrm{ZnO}$ nanoparticle size was too small and the grain size was not measurable by using SEM images. However, the shapes of $\mathrm{ZnO}$ nanoparticles were observed; they were in small spherical shapes and were well-crystallized. In Figures 4(b) and 4(c) the images were under X400 and X65 magnification, respectively. These images showed the clustered appearance of $\mathrm{ZnO}$ nanocrystals. This was clear evidence of the clustering phenomenon of nanocrystals [39].

GC-MS analysis for methanolic extract of turmeric and lemongrass is displayed in Tables $\mathbf{3}$ and $\mathbf{4}$, and Figures 5 and 6, respectively. The results showed the constituents' compounds in each of the extracts. Figure 5 shows the GC-MS chromatogram of $99 \%$ methanolic extracts of turmeric. From Table 3 , it is discovered that the most abundant compounds in methanolic extraction of turmeric was $\beta$ Turmerone, with $56.79 \%$ and Ar-Turmerone, which occupied about $28.63 \%$ was the most abundant in the composition of turmeric extract. These 2 essential oils of turmeric displayed substantial antibacterial activity. These essential compounds were documented by Negi et al. during extraction of turmeric oil using hexane as a solvent [40]. 


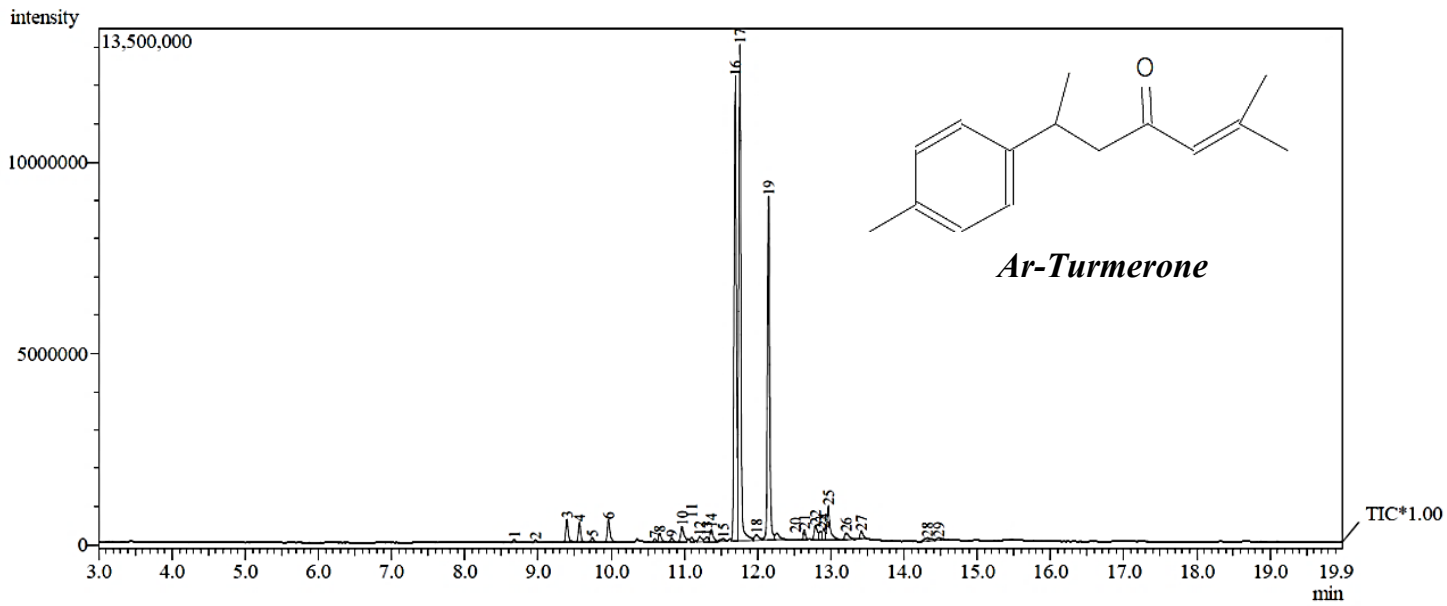

Figure 5 GC-MS chromatogram of $99 \%$ methanolic extracts of turmeric.

Figure 6 shows the GC-MS chromatogram of $99 \%$ methanolic extracts of lemongrass. Table 4 reveals that the main compound in methanolic extraction lemongrass was $\alpha$-D-Methylglucoside. This contributed to about $17.34 \%$ of the total composition of the lemongrass. This compound was obtained by using the acid-catalyzed reaction of glucose with methanol. This compound has antibacterial properties and is widely used in skincare products. Chirumbolo, in 2010, stated that methyl-glucoside is the main constituent for various plants, especially those rich with quercetin, and it has the function to act as an antibacterial agent [41].

Table 3 Composition of essential oil in turmeric.

\begin{tabular}{lc}
\hline \multicolumn{1}{c}{ Compound Name } & Percentage (\%) \\
\hline$\beta$-caryophyllene & 4.33 \\
$\alpha$-Curcumene & 1.55 \\
$\beta$-Turmerone & 56.79 \\
Gonane & 0.71 \\
Decalin & 0.32 \\
Hexamethylbenzene & 1.46 \\
(-)-isolongifolol & 0.76 \\
Perhydrotriphenylene & 1.29 \\
Butylated hydroxytoluene & 0.32 \\
Isoshyobunone & 0.77 \\
14-Beta-H-Pregna & 0.70 \\
cis-p-menth-2,8-dienol & 0.60 \\
Theaspirone & 0.82 \\
Pterosine B & 0.94 \\
Ar-Tumerone & 28.63 \\
\hline
\end{tabular}




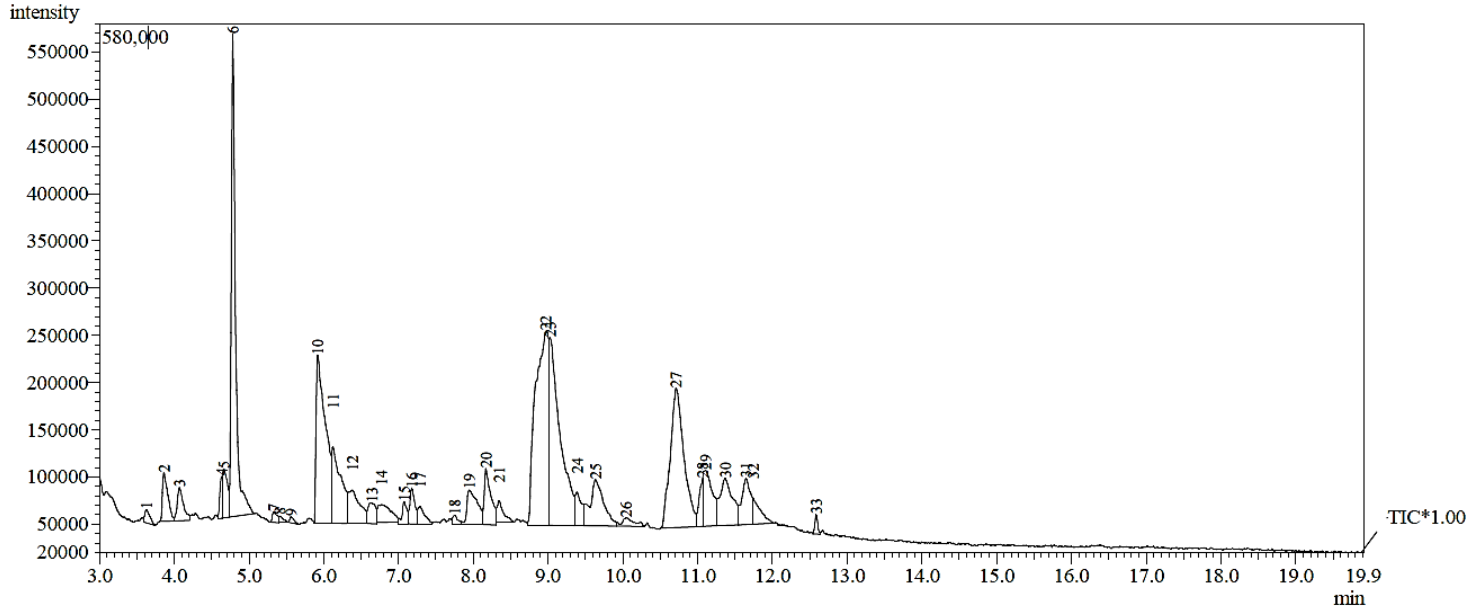

Figure 6 GC-MS chromatogram of $99 \%$ methanolic extracts of lemongrass.

Table 4 Composition of essential oil in lemongrass.

\begin{tabular}{|c|c|c|c|}
\hline R.Time & Compound Name & Compound Formula & Peak Area (\%) \\
\hline 3.628 & Trans-7-methyl-3-octene & $\mathrm{C}_{9} \mathrm{H}_{18}$ & 0.39 \\
\hline 3.861 & Melamine & $\mathrm{C}_{3} \mathrm{H}_{6} \mathrm{~N}_{6}$ & 1.57 \\
\hline 4.070 & Maltol & $\mathrm{C}_{6} \mathrm{H}_{6} \mathrm{O}_{3}$ & 1.23 \\
\hline 4.642 & Ethyl levulinate & $\mathrm{C}_{7} \mathrm{H}_{12} \mathrm{O}_{3}$ & 0.62 \\
\hline 4.611 & Glycerol & $\mathrm{C}_{3} \mathrm{H}_{8} \mathrm{O}_{3}$ & 1.39 \\
\hline 4.783 & 3,5-dihydroxy-6-methyl-2,3-dihydro4h-pyran-4-one & $\mathrm{C}_{6} \mathrm{H}_{8} \mathrm{O}_{4}$ & 12.05 \\
\hline 5.331 & 5-hydroxy-2-hydroxymethyl-1, 4-pyrone & $\mathrm{C}_{6} \mathrm{H}_{6} \mathrm{O}_{4}$ & 0.32 \\
\hline 5.411 & Citronellal & $\mathrm{C}_{10} \mathrm{H}_{20} \mathrm{O}_{2}$ & 0.12 \\
\hline 5.562 & Isopropyl 2-ethylhexanoate & $\mathrm{C}_{11} \mathrm{H}_{22} \mathrm{O}_{2}$ & 0.15 \\
\hline 5.920 & 1-Octyn-3-ol & $\mathrm{C}_{8} \mathrm{H}_{14} \mathrm{O}$ & 9.47 \\
\hline 6.123 & Glycerol & $\mathrm{C}_{5} \mathrm{H}_{10} \mathrm{O}_{4}$ & 4.24 \\
\hline 6.383 & d-Glucoheptose & $\mathrm{C}_{7} \mathrm{H}_{14} \mathrm{O}_{7}$ & 2.33 \\
\hline 6.641 & Ethyl levulinate & $\mathrm{C}_{7} \mathrm{H}_{12} \mathrm{O}_{3}$ & 0.95 \\
\hline 6.772 & 3-Isopropoxy alanine & $\mathrm{C}_{6} \mathrm{H}_{13} \mathrm{NO}_{3}$ & 1.39 \\
\hline 7.075 & Undecylenic acid & $\mathrm{C}_{11} \mathrm{H}_{20} \mathrm{O}_{2}$ & 0.65 \\
\hline 7.176 & Glutamine & $\mathrm{C}_{6} \mathrm{H}_{11} \mathrm{NO}_{4}$ & 1.11 \\
\hline 7.288 & Glycine & $\mathrm{C}_{6} \mathrm{H}_{15} \mathrm{NO}_{2} \mathrm{Si}$ & 0.72 \\
\hline 7.753 & Acetylcysteine & $\mathrm{C}_{5} \mathrm{H}_{9} \mathrm{NO}_{3} \mathrm{~S}$ & 0.27 \\
\hline 7.945 & Octyl Ester & $\mathrm{C}_{14} \mathrm{H}_{22} \mathrm{O}_{2} \mathrm{~S}$ & 2.22 \\
\hline 8.168 & Tetradecanedioic acid & $\mathrm{C}_{14} \mathrm{H}_{26} \mathrm{O}_{4}$ & 2.25 \\
\hline 8.346 & 4-Chloro-2-cresol & $\mathrm{C}_{7} \mathrm{H}_{7} \mathrm{ClO}$ & 0.75 \\
\hline
\end{tabular}




\begin{tabular}{cccc}
\hline R.Time & Compound Name & Compound Formula & Peak Area (\%) \\
\hline 8.970 & Capronic acid & $\mathrm{C}_{6} \mathrm{H}_{12} \mathrm{O}_{2}$ & 14.83 \\
9.025 & 2-Hydroxyisocaproic acid & $\mathrm{C}_{6} \mathrm{H}_{12} \mathrm{O}_{3}$ & 12.38 \\
9.386 & Butyl dimethyl silyloxy cyclopentanein & $\mathrm{C}_{11} \mathrm{H}_{24} \mathrm{OSi}$ & 1.21 \\
9.635 & Beta-D-Glucose & $\mathrm{C}_{6} \mathrm{H}_{12} \mathrm{O}_{6}$ & 3.82 \\
10.045 & Silane, trimethyl (1-methyl dodecyl oxy) & $\mathrm{C}_{16} \mathrm{H}_{36} \mathrm{OSi}$ & 0.60 \\
10.713 & $\alpha$-D-Methylglucoside & $\mathrm{C}_{7} \mathrm{H}_{14} \mathrm{O}_{6}$ & 11.40 \\
11.067 & Trimethylsilyl 5-methoxypentanoate & $\mathrm{C}_{9} \mathrm{H}_{20} \mathrm{O}_{3} \mathrm{Si}$ & 1.01 \\
11.105 & D-Galactonic acid, $\gamma$-lactone & $\mathrm{C}_{6} \mathrm{H}_{10} \mathrm{O}_{6}$ & 3.12 \\
11.370 & $\alpha$-D-Methylglucoside & $\mathrm{C}_{7} \mathrm{H}_{14} \mathrm{O}_{6}$ & 3.59 \\
11.648 & $\alpha$-D-Methylglucoside & $\mathrm{C}_{7} \mathrm{H}_{14} \mathrm{O}_{6}$ & 2.35 \\
11.742 & Geranyl-Acetate & $\mathrm{C}_{12} \mathrm{H}_{20} \mathrm{O}$ & 1.20 \\
12.586 & Dihydrojasmone & $\mathrm{C}_{11} \mathrm{H}_{18} \mathrm{O}$ & 0.32 \\
\hline
\end{tabular}

The antibacterial activity was tested via the disc diffusion method. Gentamicin $(10 \mu \mathrm{g})$ acted as a positive control due to its ability to treat infections with gram-negative and gram-positive organisms [42]. Distilled water was used as a negative control, since it does not show any antibacterial properties in any condition. The results for the levels of zones of inhibition of both gram-positive and gram-negative bacteria when tested with each antibacterial agent were placed into a table, as shown in Table $\mathbf{5}$ and Figure 7 respectively. Figures 8 and $\mathbf{9}$ show the optimum zones of inhibition after the antibacterial agents were added. It can be seen that the zones of inhibition got larger with the addition of ZnONPs.

Table 5 Assignments of the levels of zones of inhibition of gram-positive and gram-negative bacteria when tested with each antibacterial agent $(n=3)$.

\begin{tabular}{lcccccc}
\hline \multirow{2}{*}{ Organisms } & \multicolumn{7}{c}{ Samples } \\
\cline { 2 - 7 } & $\mathbf{L}$ & $\mathbf{L}+\mathbf{Z n O}$ & $\mathbf{T}$ & $\mathbf{T}+\mathbf{Z n O}$ & $\mathbf{Z n O}$ & Positive control \\
\hline Staphylococcus aureus & $0.6 \pm 0.3$ & $0.6 \pm 0.1$ & $0.5 \pm 0.0$ & $0.6 \pm 0.0$ & $0.5 \pm 0.2$ & $2.5 \pm 0.5$ \\
Escherichia coli & $1.2 \pm 0.3$ & $1.6 \pm 0.1$ & $0.5 \pm 0.1$ & $1.6 \pm 0.2$ & $1.3 \pm 0.2$ & $1.9 \pm 0.5$ \\
\hline
\end{tabular}




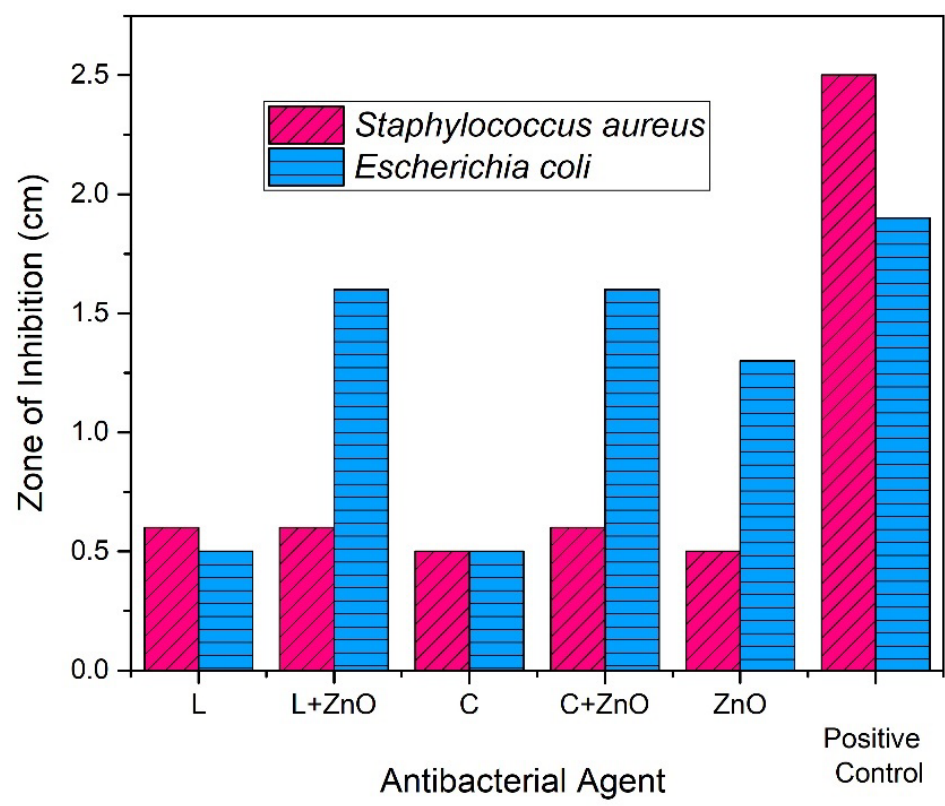

Figure 7 Assignments of the zones of inhibition of gram-positive and gram-negative bacteria when tested with each antibacterial agent.

(a)

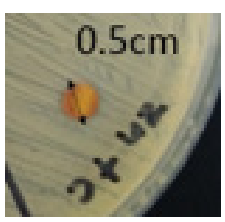

(b)

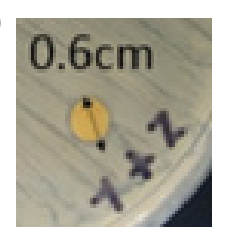

(c)

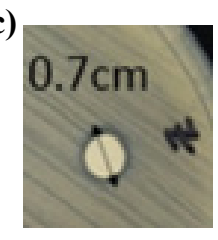

(d)

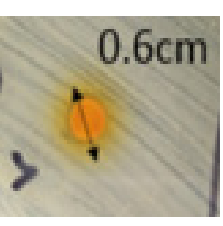

(e)

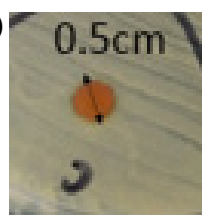

Figure 8 Zones of inhibition of Staphylococcus aureus after testing with: (a) Synergism of ZnONPs with turmeric extract; (b) Synergism of ZnONPs with lemongrass extract; (c) ZnONPs; (d) Lemongrass extract; (e) Turmeric extract.

(a)

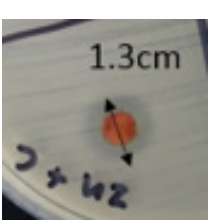

(b)

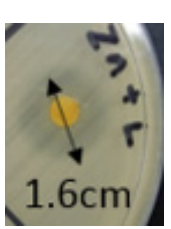

(c)

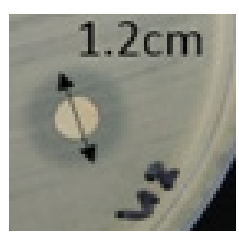

(d)

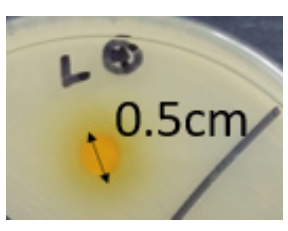

(e)

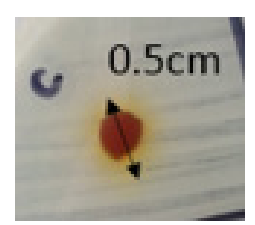

Figure 9 Zones of inhibition of Escherichia coli after testing with: (a) Synergism of ZnONPs with turmeric extract; (b) Synergism of ZnONPs with lemongrass extract; (c) ZnONPs; (d) Lemongrass extract; (e) Turmeric extract. 
http://wjst.wu.ac.th

The inhibition zones measured for both bacteria were compared. Findings revealed that zones of inhibition were higher than the results obtained by Jayandran et al. [43]. The inhibition zone (Escherichia coli) is higher in contrast to the previous research carried out by Jemal et al. in 2017 [44]. The addition of zinc oxide increased the antibacterial property. This is obvious in the case of the extract of lemongrass and turmeric alone. As soon as the zinc oxide nanoparticles came in contact with the bacteria cells, $\mathrm{Zn}^{2+}$ ions were released. The ions were then diffused into the bacteria and in turn, inhibited the growth of the bacteria. This phenomenon happened due to extremely small size of the nanoparticles. The smaller the size of the nanoparticles, the higher the efficiency of diffusion [45]. This is in agreement with the findings by Jayandran and Haneefa [36]. The mixture of nanoparticles and biomolecules significantly increased the antibacterial properties [36].

\section{Conclusions}

The synergism of zinc oxide nano-powder was successfully prepared from plant extract active compounds. The antibacterial activity was evaluated using Staphylococcus aureus and Escherichia coli. From X-ray diffraction, the crystallite size of zinc oxide nanoparticles was $17.45 \mathrm{~nm}$. FTIR analysis showed several prominent peaks for single extracts and the products of synergism. The essential peaks for lemongrass lay in the range of 1,660 to $1,820 \mathrm{~cm}^{-1}$, representing the carbonyl group with $\mathrm{C}=\mathrm{O}$ bond. For turmeric, the oleic acid, which is one of the contents of essential oil, was spotted in the region of 1,040 to $1,290 \mathrm{~cm}^{-1}$. Zinc oxide nanoparticles had spherical shapes under the observation of a Scanning Electron Microscope. The synergism of zinc oxide nano-powder enhanced the antibacterial properties of plant extracts revealed to be capable of killing the bacteria. To conclude, the synergism of zinc oxide and plant extracts needs further investigation. Antibacterial activity revealed the potential applications of green synergism of zinc oxide nano-powder. The treatment of contaminated water, medical applications, and cosmetics are among the examples it could be used for. Further study will also include in vitro and in vivo assay to test the toxicity of the samples.

\section{References}

[1] S Sarkar and SC Sarkar. Chapter-4 application of nanotechnology in medicine. Med. Sci. 2019; 117, 49.

[2] S Ali, S Rasheed, I Hassan and S Rashid. Role of nanotechnology in medicine and cancer treatment. In: Proceedings of the $5^{\text {th }}$ International Conference on Nanptechnology for Better Living, SKUAST, Shalimar Srinagar, Jammu and Kashmir, India, 2019, p. 311-2.

[3] AP Nikalje. Nanotechnology and its applications in medicine. Med. Chem. 2015; 5, 81-9.

[4] Y Liu, L Shi, L Su, HCVD Mei, PC Jutte, Y Ren and HJ Busscher. Nanotechnology-based antimicrobials and delivery systems for biofilm-infection control. Chem. Soc. Rev. 2019; 48, 42846.

[5] PV Sekar, VD Parvathi and R Sumitha. Green nanotechnology in cadmium sulphide nanoparticles and understanding its toxicity and antimicrobial properties. Biomed. Res. 2019; 30, 805-9.

[6] P Li, J Li, C Wu, Q Wu and J Li. Synergistic antibacterial effects of $\beta$-lactam antibiotic combined with silver nanoparticles. Nanotechnology 2005; 16, 1912.

[7] AE Allen and DWC Macmillan. Synergistic catalysis: A powerful synthetic strategy for new reaction development. Chem. Sci. 2012; 3, 633-58.

[8] J Jiang, J Pi and J Cai. The advancing of zinc oxide nanoparticles for biomedical applications. Bioinorg. Chem. Appl. 2018; 2018, 1062562.

[9] K Ranoszek-Soliwoda, E Tomaszewska, K Małek, G Celichowski, P Orlowski, M Krzyzowska and J Grobelny. The synthesis of monodisperse silver nanoparticles with plant extracts. Colloids Surf. B Biointerfaces 2019; 177, 19-24.

[10] S Iravani, H Korbekandi, SV Mirmohammadi and B Zolfaghari. Synthesis of silver nanoparticles: Chemical, physical and biological methods. Res. Pharm. Sci. 2014; 9, 385-406. 
http://wjst.wu.ac.th

[11] MI Naik, BA Fomda, E Jaykumar and JA Bhat. Antibacterial activity of lemongrass (Cymbopogon citratus) oil against some selected pathogenic bacterias. Asian Pac. J. Trop. Med. 2010; 3, 535-8.

[12] Bhawana, RK Basniwal, HS Buttar, VK Jain and N Jain. Curcumin nanoparticles: Preparation, characterization, and antimicrobial study. J. Agric. Food Chem. 2011; 59, 2056-61.

[13] H Mirzaei and M Darroudi. Zinc oxide nanoparticles: Biological synthesis and biomedical applications. Ceram. Int. 2017; 43, 907-14.

[14] SZ Moghadamtousi, HA Kadir, P Hassandarvish, H Tajik, S Abubakar and K Zandi. A review on antibacterial, antiviral, and antifungal activity of curcumin. Biomed. Res. Int. 2014; 2014, 186864.

[15] A Azam, AS Ahmed, M Oves, MS Khan, SS Habib and A Memic. Antimicrobial activity of metal oxide nanoparticles against Gram-positive and Gram-negative bacteria: A comparative study. Int. J. Nanomedicine 2012; 7, 6003-9.

[16] K Das, RKS Tiwari and DK Shrivastava. Techniques for evaluation of medicinal plant products as antimicrobial agent: Current methods and future trends. J. Med. Plants Res. 2010; 4, 104-11.

[17] M Shah, D Fawcett, S Sharma, SK Tripathy and GEJ Poinern. Green synthesis of metallic nanoparticles via biological entities. Materials (Basel) 2015; 8, 7278-308.

[18] NE Tajidin, SH Ahmad, AB Rosenani, H Azimah and M Munirah. Chemical composition and citral content in lemongrass (Cymbopogon citratus) essential oil at three maturity stages. Afr. J. Biotechnol. 2012; 11, 2685-93.

[19] AA Alafiatayo, S Ahmad and M Maziah. Total antioxidant capacity, total phenolic compounds and the effects of solvent concentration on flavonoid content in Curcuma longa and Curcuma xanthorhhiza rhizomes. Med. Aromat. Plants 2014; 3, 1-4.

[20] B Balakrishnan, S Paramasivam and A Arulkumar. Evaluation of the lemongrass plant (Cymbopogon citratus) extracted in different solvents for antioxidant and antibacterial activity against human pathogens. Asian Pac. J. Trop. Dis. 2014; 4, S134-S139.

[21] SO Ogunyemi, Y Abdallah, M Zhang, H fouad, X Hong, E Ibrahim, MMI Masum, A Hossain, J Mo and B Li. Green synthesis of zinc oxide nanoparticles using different plant extracts and their antibacterial activity against Xanthomonas oryzae pv. oryzae. Artif. Cells Nanomed. Biotechnol. 2019; 47, 341-52.

[22] AM Awwad, MW Amer, NM Salem and AO Abdeen. Green synthesis of zinc oxide nanoparticles (ZnO-NPs) using Ailanthus altissima fruit extracts and antibacterial activity. Chem. Int. 2020; 6, 151-9.

[23] Y Fukuyama, N Yasuda, K Sugimoto and S Kimura. X-ray diffraction measurement of a single nanometre-sized particle levitated in air by an optical-trap sample holder. J. Synchrotron Radiat. 2020; 27, 67-74.

[24] Y Gao, MAV Anand, V Ramachandran, V Karthikkumar, V Shalini, S Vijayalakshmi and D Ernest. Biofabrication of zinc oxide nanoparticles from aspergillus niger, their antioxidant, antimicrobial and anticancer activity. J. Clust. Sci. 2019; 30, 937-46.

[25] OJ Nava, PA Luque, CM Gómez-Gutiérrez, AR Vilchis-Nestor, A Castro-Beltran, ML MotaGonzalez and A Olivas. Influence of Camellia sinensis extract on zinc oxide nanoparticle green synthesis. J. Mol. Struct. 201; 1134, 121-5.

[26] R Waseem and KH Low. Advanced analytical techniques for the extraction and characterization of plant-derived essential oils by gas chromatography with mass spectrometry. J. Sep. Sci. 2015; 38, 483-501.

[27] ND Bharadwaj and AK Sharma. Detection of escherichia coli, staphylococcus aureus and salmonella typhi in drinking water of government institutions and organizations of gwalior city. Int. J. Eng. Sci. Res. Technol. 2016; 5, 769-74.

[28] A Altemimi, N Lakhssassi, A Baharlouei, DG Watson and DA Linghtfoot. Phytochemicals: Extraction, isolation, and identification of bioactive compounds from plant extracts. Plants (Basel) $2017 ; 6,42$.

[29] S Vijayakumar, K Saravanakumar, B Malaikozhundan, M Divya, B Vaseeharan, EF Duran-Lara and $\mathrm{MH}$ Wang. Biopolymer K-carrageenan wrapped $\mathrm{ZnO}$ nanoparticles as drug delivery vehicles for anti MRSA therapy. Int. J. Biol. Macromol. 2020; 144, 9-18. 
http://wjst.wu.ac.th

[30] AK Zak, WHA Majid, ME Abrishami and R Yousefi. X-ray analysis of ZnO nanoparticles by Williamson-Hall and size-strain plot methods. Solid State Sci. 2011; 13, 251-6.

[31] NI Rasli, H Basri and Z Harun. Zinc oxide from aloe vera extract: Two-level factorial screening of biosynthesis parameters. Heliyon 2020; 6, e03156.

[32] TS Anvekar, VR Chari and H Kadam. Green synthesis of ZnO nanoparticles, its characterization and application. Mat. Sci. Res. India 2017; 14, 153-7.

[33] RI Uchegbu, LC Ngozi-Olehi and RU Ogbuneke. Essential oils composition of Curcuma longa rhizome from Nigeria. Am. J. Chem. Appl. 2014; 1, 1-5.

[34] BK Paul, MMU Munshi, MN Ahmed, GC Saha and SK Roy. The fatty acid composition and properties of oil extracted from fresh rhizomes of turmeric (Curcuma longa Linn.) cultivars of Bangladesh. Bangladesh J. Sci. Ind. Res. 2011; 46, 127-32.

[35] LA Araujo, RGM Araujo, FO Gomes, SR Lemes, LM Almeida, LJQ Maia, PJ Gonçalves, F Mrué, NJ Silva-Junior and PRDE Melo-Reis. Physicochemical/photophysical characterization and angiogenic properties of Curcuma longa essential oil. An. Acad. Bras. Cienc. 2016; 88, 1889-97.

[36] M Jayandran and M Haneefa. Green synthesis and antimicrobial activity studies of Curcuminaline functionalized zinc oxide nanoparticles and comparative studies with its non-functionalized form. Int. J. Pharm. Sci. Res. 2016; 7, 4117-24.

[37] B Kumar, V Singh, R Shankar, K Kumar and RK Rawal. Synthetic and medicinal prospective of structurally modified curcumins. Curr. Top. Med. Chem. 2017; 17, 148-61.

[38] RN Moussawi and D Patra. Nanoparticle self-assembled grain like curcumin conjugated ZnO: Curcumin conjugation enhances removal of perylene, fluoranthene, and chrysene by ZnO. Sci. Rep. $2016 ; 6,24565$.

[39] AS Elfeky, SS Salem, AS Elzaref, ME Owda, HA Eladawy, AM Saeed, MA Awad, RE Abou-Zeid and A Fouda. Multifunctional cellulose nanocrystal/metal oxide hybrid, photo-degradation, antibacterial and larvicidal activities. Carbohydr. Polym. 2020; 230, 115711.

[40] P Negi, M Aggarwal, G Sharma, C Rathore, G Sharma, B Singh and OP Katare. Niosome-based hydrogel of resveratrol for topical applications: An effective therapy for pain related disorder(s). Biomed. Pharmacother. 2017; 88, 480-7.

[41] S Chirumbolo. The role of quercetin, flavonols and flavones in modulating inflammatory cell function. Inflamm. Allergy Drug Targets 2010; 9, 263-85.

[42] JM Al-Shuneigat, SA Al-Sarayreh, MA Al-Qudah and YM Al-Saraireh. Antibacterial and antibiofilm activity of essential oil of Achillea biebersteinii and its mode of action. J. Pharm. Pharmacogn. Res. 2020; 8, 155-66.

[43] M Jayandran, M. Haneefa and V Balasubramanian. Biosynthesis and antimicrobial activity studies of salicylalchitosan functionalized zinc oxide nanoparticles and comparative studies with its nonfunctionalized form. Orient. J. Chem. 2016; 32, 719-25.

[44] K Jemal, BV Sandeep and S Pola. Synthesis, characterization, and evaluation of the antibacterial activity of Allophylus serratus leaf and leaf derived callus extracts mediated silver nanoparticles. $J$. Nanomater. 2017; 2017, 1-11.

[45] YN Slavin, J Asnis, UO Häfeli and H Bach. Metal nanoparticles: understanding the mechanisms behind antibacterial activity. J. Nanobiotechnol. 2017; 15, 65. 